\title{
Slumps and Jumps: Another Look at Developmental Changes in Creative Abilities
}

\section{Jacek Gralewski}

The Maria Grzegorzewska University, Poland

E-mail address: jacekgralewski@ o2.pl

\section{Aleksandra Gajda}

The Maria Grzegorzewska University, Poland

E-mail address: agajda@aps.edu.pl

\section{Ewa Wiśniewska}

The Maria Grzegorzewska University, Poland

E-mail address: ewawisniewska@aps.edu.pl

\author{
Izabela Lebuda \\ The Maria Grzegorzewska University, Poland \\ E-mail address: izalebuda @aps.edu.pl \\ Dorota M. Jankowska \\ The Maria Grzegorzewska University, Poland \\ E-mail address: djankowska@aps.edu.pl
}

\section{ARTICLE INFO}

\section{Keywords:}

Creativity

Developmental changes

Life span on creativity

Test for Creative Thinking

- Drawing Production (TCT-DP)

Slump in creativity

\section{Article history:}

Received 16 May 2016

Received in revised form 24 May 2016

Accepted 25 May 2016

ISSN: 2354-0036

DOI: 10.1515/ctra-2016-0011
A B STR A C T

The aim of this study is the analysis of creativity changes across life, particularly the widely discussed crisis periods in the development of creative abilities. A large and diversified sample of Poles ( $N=4898$ aged from 4 to 21 years), at each educational stage of the Polish education system, from pre-schoolers, through primary school students, middleschool students, secondary-school students and finally university students completed the Test for Creative Thinking Drawing Production. The observed changes showed a nonlinear pattern in the development of creativity with diverse declines and increases in creative abilities. These trends are different for each of the assessment criteria of the TCT-DP and at least three different trajectories were identified. The adolescent slump was confirmed for three of the 14 assessment criteria as well as the total TCT-DP score. What was not noted however was: a slump caused by entry into formal schooling, (age 6 vs 7), 4th grade slump, (age 9 vs 10) and 6th grade slump (age 11 vs 12). We discuss possible reasons for and consequences of the findings.

Developmental trends in levels of creative ability have been the subject of researcher scrutiny for nearly half a century (see e.g. Kim, 2011; Smith \& Carlsson, 1983, 1985, 1990; Torrance, 1968). It has been shown that several "slumps and jumps" take place between childhood and adulthood in the development of creative ability, that is, at moments

\footnotetext{
"The study was supported by the Polish Ministry of Science and Higher Education for Jacek Gralewski (luventus Plus Program IP 2014 013373), Izabela Lebuda (luventus Plus Program, 0252/IP3/2015/73), the National Science Centre (NSC), Poland (grant for Aleksandra Gajda, UMO-2011/03/N/HS6/05073 and for Dorota M. Jankowska, UMO 2011/03/ N/HS6/05153).
} 
of regress and progress (peaks) (Camp, 1994; Krampen, 2012; Lau \& Cheung, 2010; Runco, 1999). However, based on the research published so far, no unambiguous conclusions can be drawn. Some researchers doubt whether fluctuations in the development of creativity do in fact occur (Charles \&Runco, 2000-2001; Cheung, Lau, Chan \& Wu, 2004; Sak \& Maker, 2006), how many there are, when they occur, and how long they last (see e.g. Charles \& Runco, 2000-2001; Kim, 2011; Krampen, 2012; Claxton, Pannells, \& Rhoads, 2005).

The aim of this paper is to track developmental trends in creative abilities as defined and measured according to Urban's model (1990). In comparison to previous research into this question (see Jaarsveld, Lachmann, \& van Leeuwen, 2012; Maker, Jo \& Muammar, 2008; Urban, 1991), the research at hand was conducted on a large sample $(\mathrm{N}=4898)$ and results are shown in age groups from early childhood up to early adulthood.

\section{Developmental Trends in Creativity}

Hitherto research into the relationship between age and the level of creative ability has yielded different, sometimes conflicting, models of development: from the nearly linear (Cheung et al., 2004; Lopez, Esquivel, \& Houtz, 1993; Sak \& Maker, 2006), through J-shaped patterns (from grade 5 to 9 - Lau \& Cheung, 2010; from age 2 to 57 - Smolucha \& Smolucha, 1985), and inverted J-shaped patterns (from grade 1 to 5 - Besançon \& Lubart, 2008; from age 20 to 100 - McCrae, Arenberg, \& Costa, 1987), U-shaped patterns (from grade 3 to 5 - Torrance, 1968), and inverted U-shaped patterns ( from grade 1 to 12 - Camp, 1994; from grade 3 to 5; Charles \& Runco, 2000-2001; from kindergarten to high school - Kim, 2011), to the more complex stadial-phasic models (Krampen, 2012). Abundant research indicates a lack of continuity in the development of creative ability between childhood and adolescence (13-14 age range) (e.g. Chae, 2003; He \& Wong, 2015; Kleibeuker, de Dreu, \& Crone, 2013; Krampen, 2012; Lau \& Cheung, 2010). Most attention has been paid to creativity slumps, i.e. the observed decline in creative ability as measured by divergent thinking tests. In Daugherty's analyses (1993) the earliest crisis was identified as early as between the ages of 3 and 6 ; however, most often it is the age range of 6-7 - at the very beginning of primary school, upon entering formal schooling that is most commonly indicated as the most likely period for the first crisis to occur (Krampen, 2012; Smith \& Carlsson, 1983; Urban, 1991). Moreover, the so-called "fourth grade crisis" occurs between the ages of nine and 10 (Lubart \& Lautrey, 1995; Rosenblatt \& Winner, 1988; Torrance, 1968, 1977), followed by another in primary school grades 5-6 at the age of 10-12 (Claxton, et al., 2005; Kim, 2011; Krampen, 2012; Lau \& Cheung, 2010; Smith \& Carlsson, 1985, 1990), and the less frequently mentioned - 
and often treated as the pinnacle of the former - a crisis in adolescence (Camp, 1994; Jastrzębska \& Limont, 2015; Kim, 2011; Kleibeuker, et al., 2013). There is much less research into the development of creative ability in adults. According to the Peak and Decline Model (Levy \& Langer, 1999), it is assumed that the level of creative ability grows until the late 30s, and then gradually declines (Alpaugh, Parham, Cole, \& Birren, 1982; Guilford, 1967). Based on research into people over 20 years of age, a curvilinear trend has been established in the scope of changes in the level of associational, expressional, ideational and word fluency, with an increase in scores for men under 40 years and a decline thereafter (McCrae, et al., 1987).

In the case of children and teenagers developmental trends vary depending on the type of creative ability considered in the analyses (Claxton, et al., 2005; Kim, 2011; Kleibeuker et al., 2013). Based on six normalization studies for the Torrance Test of Creative Thinking - Figural Version, differences in developmental trajectories have been noted for fluency, originality and elaboration (Kim, 2011). Fluency grows in children between the age of 5 and 8 (from kindergarten to grade 3), it then stabilizes (ages 8-10, grades 3-5), and declines after age 10 (grade 5) until adulthood. Originality grows linearly from the age of 5 until the age of 10 (from kindergarten to grade 5), then decreases, reaches its lowest level in secondary school, and rises again in adulthood (Kim, 2011). Elaboration increases linearly from kindergarten until as late as age 10 (grade 5), stabilizes a year later (grade 6), and then grows until as late as secondary school, to then decline significantly in adulthood. However, in comparing differences in the development of each creative ability of primary school students (grades 4 to 9), different regularities have been noted for students of grades 4 and 9: a rise in elaboration and decrease in originality (the lowest being that of grade 6) and a lack of differences in levels of fluidity and flexibility (Claxton, et al., 2005).

Developmental trends in creativity are also related to the nature of the task. A study that made use of the Test de CreatividadInfantil (TCI) (Child Creativity Test - Romo, Alfonso-Benlliure, \& Sánchez-Ruíz, 2008) indicates, that - in the case of interconnection of figures and the complexity of the composition carried out - an ascendant trajectory occurs; in variables that are impacted by attitudes and motivation such as originality, a trajectory with ups and downs is noted; in the case of tasks requiring experience and knowledge which measure verbal as well as shape creating skills, an upward trend was discovered. A stable trajectory was noted for the Atypical Manipulation variable (AlfonsoBenlliure \& Santos, 2016).

It may be assumed, that the ambiguity of findings from previous research into trends for creative ability, in part stems from between-country cultural differences in child rearing 
and school functioning (Dahlman, Bäckström, Bohlin, \& Frans, 2013; Fearon, Copeland, \& Saxon, 2013; Torrance, 1968). In Poland, the dominant model of secondary school education is that in which it is intelligence and not creativity that forms the principle characteristic for evaluation of students' performance (Gralewski \& Karwowski, 2012), which results in misconceptions about creative students on the part of teachers and contributes to their inability to recognize creativity in their students (Gralewski \& Karwowski, 2013, 2016); this in turn may have an impact on the development of creative abilities in the students themselves.

\section{Causes of "slumps and jumps" in the development of creative ability}

Individual characteristics and environmental factors, as well as the occurrence of "slumps and jumps" (Maker et al., 2008), are considered to be at the root of the development of creativity. The existence of four potential sources of slumps and jumps is suggested: (a) biological development, especially on the neuronal and hormonal levels (Barbot \& Tinio, 2015; Diamond, 2002; Dietrich, 2004), (b) the correspondent cognitive development, including the ability to conduct intellectual operations as well as acknowledgment of one's capabilities in this regard (Charles \& Runco, 2000-2001; Kleibeuker, et al., 2013; Piaget, 1962; Runco \& Charles, 1997; Vygotsky, 1930/2004, 1931/1991), (c) psychosocial needs typical for the given developmental stage (Cropley, 2001; Erikson, 1968; Kohlberg, 1981; Maker, et al., 2008; Rothenberg, 1990), and (d) environmental factors, especially those present in schools (Cropley, 2001; Gardner, 1982; Lau \& Cheung, 2010; Runco \& Charles, 1997; Smith \& Carlsson, 1990), including stress-inducing experiences related to the transition between successive stages of education, i.e. school transition stress (He \& Wong, 2015; Krampen, 2012).

The reasons for the first of the crises - upon entry into formal schooling (Maker et al., 2008) - are sought in the transition from the preoperational stage ranges (from about ages 2 to 7 ) to the concrete operational stage (typically ages 7 to 11) as defined in Piagetian and neo-Piagetian theories (e.g. Marchand, 2012; Piaget, 1950). This entails a shift from egocentric to sociocentic thinking, which causes the children to become more susceptible to the power of authority and thus more willing to abide by rules and specified rules (Runco \& Charles, 1997). These changes may also be required by the need for competence, which leads to limiting spontaneous play and creative expression in the name of diligence and propriety. School discipline and the challenges of taking on the role of a student are also suggested as having negative impact on creativity (Cropley, 2001; Gardner, 1982; Runco \& Charles, 1997; Smith \& Carlsson, 1990). This includes socializing to submit to rules and the stimulation of convergent thinking (Krampen, 2012). 
In this period the child's inner speech is substituted with utterances directed towards rising to the challenges of the task (Cropley, 2001). This is a result of internalization of language which occurs in social situations, changes in speech structure - from external speech to inner speech, and its function - from communication to a self-regulating function, which improves one's ability to tell the difference between reality and its inner, mental representations (e.g. Ayman-Nolley, 1992; Vygotsky, 1934/1986). The crisis in this period may also result from the development of the dorsolateral prefronal cortex (DLPFC), responsible for e.g. concentration which is necessary for tasks which are new, complex and requiring a change of perspective. As a result, children between the ages of 5 and 7 experience a significant improvement in memory strategy utilization and systematization of knowledge, despite the still sub-optimal functioning of the inhibitor of control (Diamond, 2002), and this may in turn result in a tendency to recall known solutions rather than their actual creation (Benedek et al., 2013).

The source of the second of the crises referred to as the fourth grade slump is most commonly sought in a strong need for acceptance, which causes children to adapt to patterns established by peers and set out by self-selected authority figures. Much like in the previous crisis, stress related to transitioning to the next stage of education as well as a strong need to meet school requirements and relevant expectations for in-class conduct are also of significance (He \& Wong, 2015; Kim, 2011; Marcon, 1995; Torrance, 1977). As a result of the necessity to meet schooling expectations, children of this age may be particularly oriented towards providing precise and appropriate answers, which may have negative impact on the originality of the provided solutions (Charles \& Runco, 2000-2001; Kim, 2011). It is also suggested that another reason for the crisis is the child's acquisition of critical evaluative skills, which in turn results in focusing on real ideas, rather than creative solutions (Runco, 1991). What may prove to be of significance is also the child's transition from the pre-conventional stage of moral development, characterized by individualism, egocentrism and egoism, towards the conventional stage of moral development, the core of which lies in social approval (Kohlberg, 1981). At this time children become more oriented in social conventions and adjust personal wants and actions with regard to standards and forms of conduct valued by their peers, authority figures and the immediate milieu. Thus a fear of undertaking creative activity which may result in rejection grows.

The causes of the sixth grade slump includes the development of logical thinking and reasoning ability (Kim, 2011). This is connected with the nature of cognitive development. At about 10-11 years of age - as a result of the continuing maturation of the frontal lobe - the capacity to restrain impulses deemed redundant or erroneous increases signifi- 
cantly. Excessive control over the incoming surge of information may lead to a decrease in creativity in this regard (Zabelina, O'Leary, Pornpattananangkul, Nusslock, \& Beeman, 2015; Zedelius \& Schooler, 2015). Another potential cause of the crisis in this period is the conflict of conformity and individuality, the contradictory striving towards acceptance of significant persons and the development of independence and self-identity (Claxton, et al., 2005).

One of the reasons for the creativity slump in adolescence may also lie in the psychosocial development of people at this age. According to Erikson's (1968) psychosocial approach, the central integrating construct for understanding psychological development during adolescence is considered to be identity and the relevant crisis of the identity vs. role confusion. At this time one's identity is being formed which also requires deciding on group affiliation, identifying oneself with it, being accepted by its members, as well as confronting models of adulthood and environmental pressure (Barbot \& Heuser; in press). The crisis leading to defining one's individual identity which occurs in the moratorium period (Marcia, 1994) unfolds through exploring and adjusting the self to various ideological convictions, social and professional roles, which impacts one's creative functioning (Dollinger, Dollinger, \& Centeno, 2005). Other potential reasons for the creativity slump in this period include hormonal change, especially the spike in testosterone (Hassler \& Nieschlag, 1989), whose above-optimal levels may adversely impact creativity (Karwowski \& Lebuda, 2014; Karwowski \& Lebuda, in press). The crisis might also be caused by neuronal changes, especially a pruning process in the pre-frontal cortex (Nelson \& Guyer, 2011) and the process of myelination related to increased integration of distributed brain areas (Barbot \& Tinio, 2015; Spear, 2013).

\section{Methodological limitations of previous studies}

Two aspects of previous research are particularly limiting to potential generalizations of the obtained results, the first being non-random and often under-powered sampling, the other being a lack of analyses of potential biasing of the tests against people of different ages.

Despite convincing reasons for including teenagers and young adults in studies into creative ability (Kim, 2011; Kleibeuker, et al., 2013), research is usually conducted on children between the ages of six and 14 (Lau \& Cheung, 2010; Krampen, 2012; Sak \& Maker, 2006). Furthermore, the age range is typically limited to a difference of 2-3 years or grade levels (Chae, 2003; Charles, Runco, 2000-2001; He \& Wong, 2015), and also of concern is the sample size at each age strata (Claxton, et al., 2005; Jaarsveld, et al., 2012; Kleibeuker, et al., 2013; Sak \& Maker, 2006; Urban, 1991). 


\section{The Present Study}

Considering the above-mentioned limitations, we decided to track changes in levels of creative ability since early childhood through to early adulthood (4-21 year of age). We chose the Test for Creative Thinking - Drawing Production (TCT-DP; Urban \& Jellen, 1996) which has rarely been utilized for this purpose.

\section{METHOD}

\section{Participants}

The study involved a total of 4854 people (54.7\% women) aged from 4 to 21 ( $M=12.43$, $S D=4.41)$. Study participants included pre-schoolers $(N=466,9.6 \%)$ from age 4 to 6 , primary school students $(\mathrm{N}=2011,41.4 \%)$ from age 7 to 12 and grade levels from 1 to 6 , middle-school students ( $N=744,15.3 \%$ ) from age 13 to 15 and grade levels from 7 to 9 , secondary-school students $(\mathrm{N}=1426,29.4 \%)$ from age 16 to 18 and grade levels from 10 to 12 , and university students ( $N=207,4.3 \%$ ) from age 19 to 21 living in different places in central Poland. Detailed data about the age of the participants and the type of school they attended is provided in Table 1.

\section{Measure}

In order to investigate creativity level, the Urban, Jellen Test of Creative Thinking - Drawing Production (TCT-DP) was used (Urban, 1991; Urban \& Jellen, 1996). The purpose of the test is to complete a drawing, starting from six elements placed asymmetrically on the test sheet. Five of them are placed inside a square border and one outside. The created drawing is assessed using the following criteria: Continuations ( $\mathrm{Cn}$ ), Completions $(\mathrm{Cm})$, New elements $(\mathrm{Ne})$, Connections made with a line $(\mathrm{Cl})$, Connections that contribute to a theme (Cth), Boundary breaking that is fragment-dependent (Bfd), Boundary breaking that is fragment-independent (Bfi), Perspective $(\mathrm{Pe})$, Humour and affectivity $(\mathrm{Hu})$, Unconventionality with subcriteria (Uc) [(a) manipulation of the test material (Uca); (b) surrealistic or abstract elements (Ucb); (c) use of symbols or signs (Ucc); (d) unconventional usage of the given fragments (Ucd)] and Speed (Sp). The final TCT-DP score is the sum of points for these criteria. In this study, the reliability of the TCT-DP in the total sample was acceptable $(\alpha=.73)$. The reliability of the TCT-DP in each of the age groups was acceptable, and fell within the $\alpha=.65$ to $\alpha=.82$ range (Table 1 ). The vast majority of rating criteria of the TCT-DP was characterized by an acceptable discriminatory power. 


\section{Table 1}

Sample characteristic and coefficients of internal consistency (Cronbach's $\alpha$ ) of the Test of Creative Thinking - Drawing Production between age levels

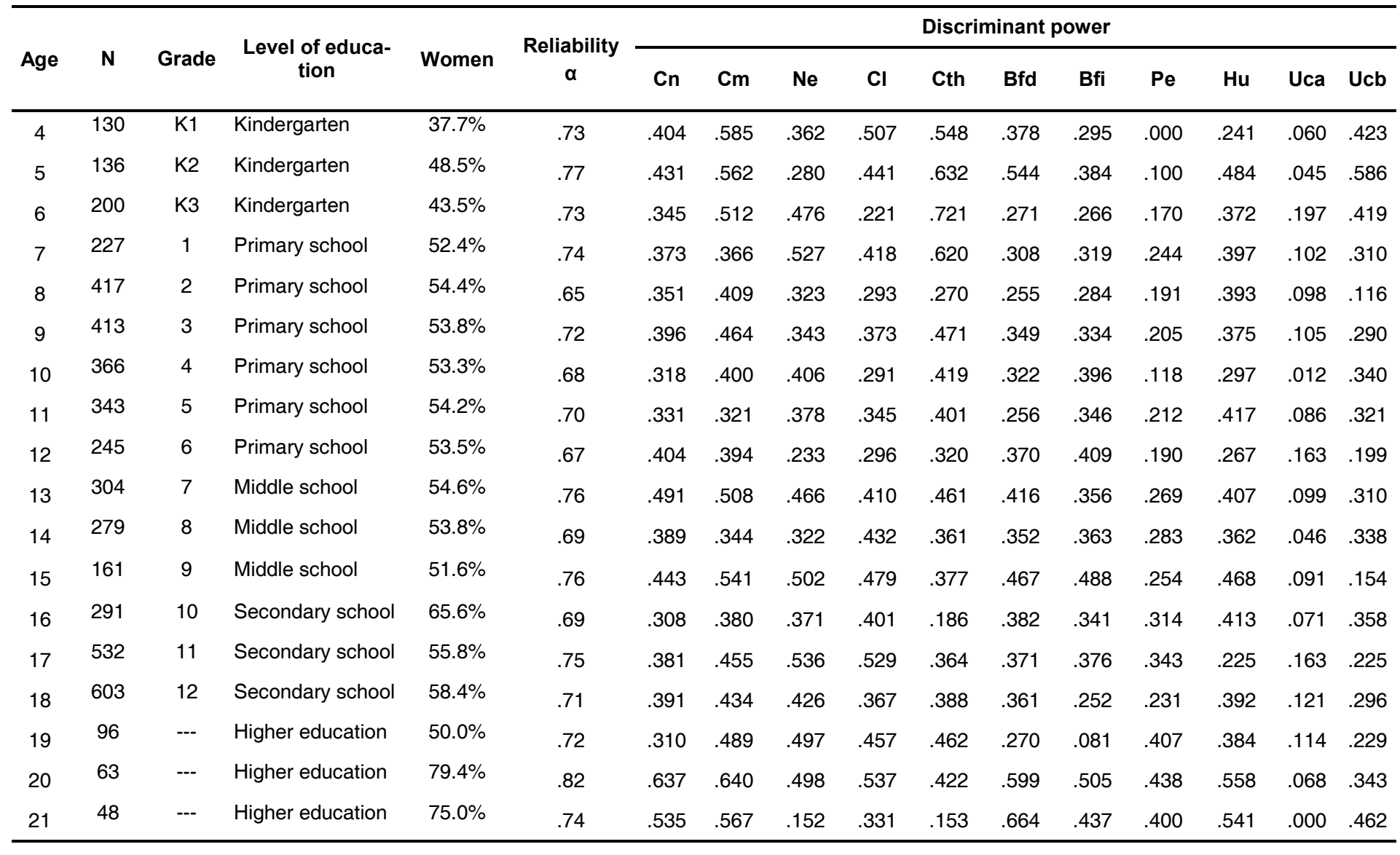

\section{Procedure}

Each participant was informed about the purpose and course of the study. Participation in the study was confirmed by written consent. In the case of children and adolescents, parents or carers signed the consent. The subjects were tested in a group setting.

\section{Results}

\section{Developmental changes in the level of creative abilities}

To analyze changes in the levels of creative ability as measured by each of the TCT-DP criteria between the age groups under investigation a multivariate analysis of variance (MANOVA) was conducted; this allowed for controlling of type I errors. Wilks' lambda $F$ $(238,51882.13)=11.89, p<.001, \eta^{2}=.04$ confirmed differences in levels of creative ability measured by each of the TCT-DP criteria between participants from different age groups. In cases when the $F$ value of MANOVA was significant for each of the criteria of the TCT-DP post hoc tests (e.g., Tukey HSD Test) were conducted. Next eta-squared values were calculated to indicate the effect sizes for all $F$ values. Detailed data concerning developmental change in the levels of creative ability measured with the TCT-DP are provided in table 2 and figure 1. 


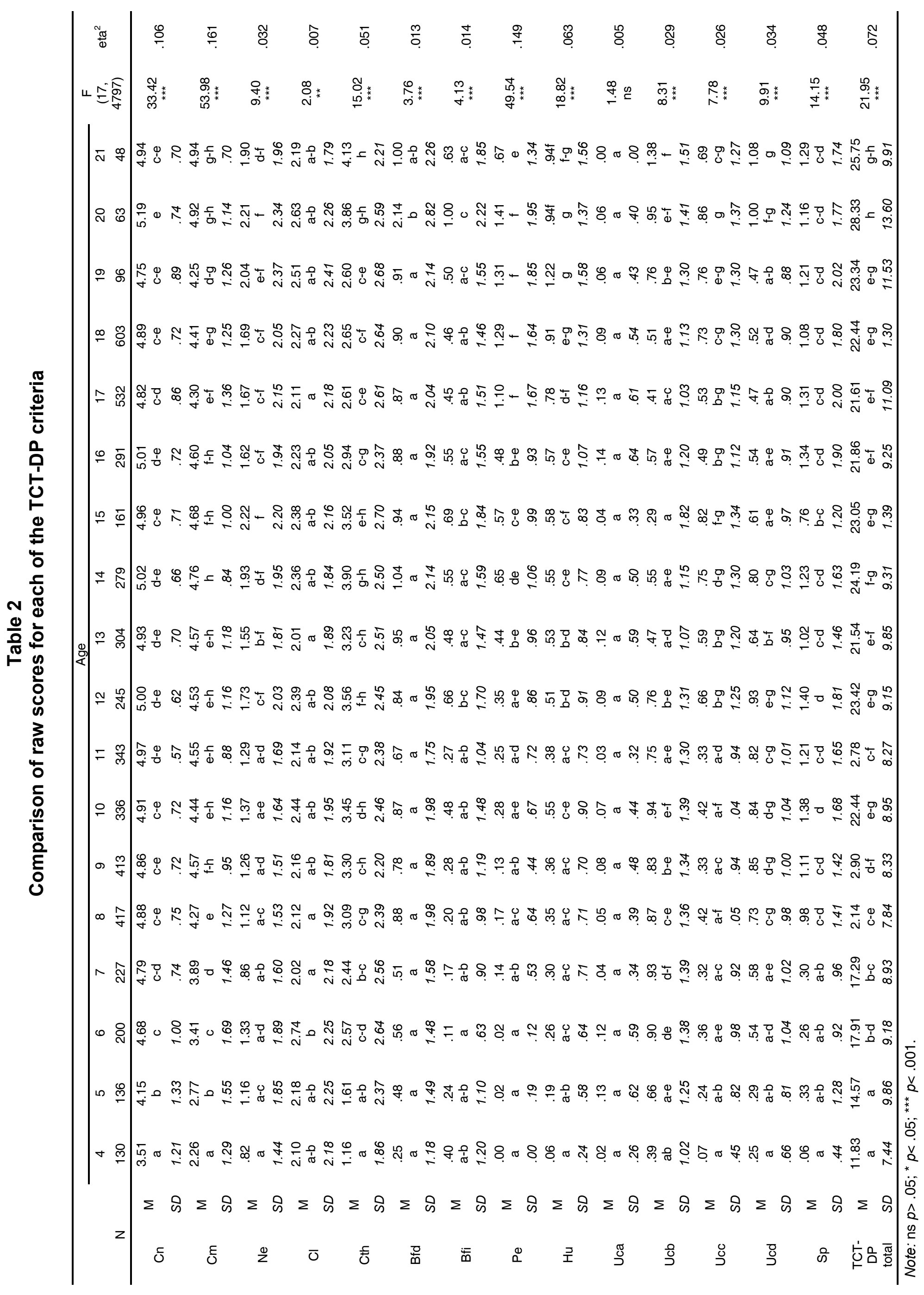



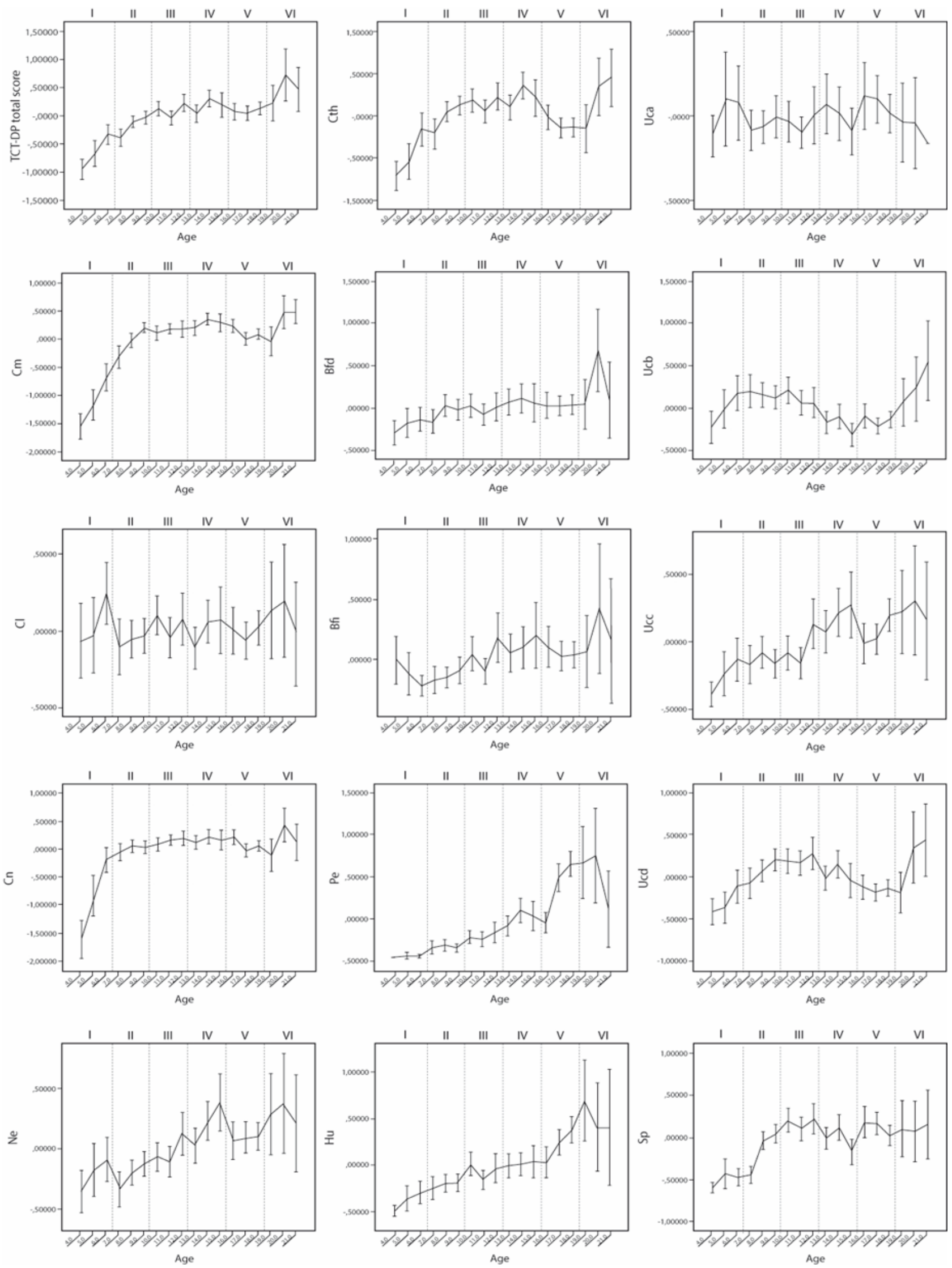

Figure 1

Developmental changes in creative abilities between age levels (error bars $95 \% \mathrm{Cl}$ ).

Note: I-kindergarten, II-primary school (grade 1-3), III-primary school (grade 4-6), IV-middle school, Vsecondary school, VI-higher education 
Continuations (Cn). The number of continuations used in the TCT-DP changes significantly with age $F(17,4797)=33.42, p<.001, \eta^{2}=.106$. The number of continuations rises notably year by year from $4(M=3.51 ; S D=1.21)$ to 6 years of age $(M=4.68$; $S D=1.00)$, in the 6 to 8 age range $(M=4.88$; $S D=.75)$ the increase loses momentum, and between the ages of 8 and $16(M=5.01 ; S D=.72)$ the number of continuations stabilized at a similar level. Between the ages of $17(M=4.82$; $S D=.86)$ and $19(M=4.75$; $S D=.89$ ) a non-significant decrease in the number of continuations takes place, followed by another rise at the age of $20(M=5.19 ; S D=.74)$ and $21(M=4.94 ; S D=.70)$. Although a minor decrease in the number of continuations was noted between the ages of $17-19$, no crisis was noted in the development of this ability (Table 3 ).

Table 3

Slumps in creativity and evaluation criteria for the TCT-DP

\begin{tabular}{|c|c|c|c|c|}
\hline & $\begin{array}{c}\text { Slump caused by } \\
\text { entry into formal } \\
\text { schooling } \\
\text { (6 vs } 7 \text { age) } \\
\end{array}$ & $\begin{array}{l}\text { Fourth grade } \\
\text { slump } \\
\text { (9 vs } 10 \text { age) }\end{array}$ & $\begin{array}{l}\text { Sixth grade } \\
\text { slump } \\
\text { (11 vs } 12 \text { age) }\end{array}$ & Adolescent slump \\
\hline $\mathrm{Cn}$ & No & No & No & No \\
\hline $\mathrm{Cm}$ & No & No & No & Yes $(14>17,18)$ \\
\hline $\mathrm{Ne}$ & No & No & No & No \\
\hline $\mathrm{Cl}$ & Yes & No & No & No \\
\hline Cth & No & No & No & Yes $(14>16,17,18$ and $15>17,18)$ \\
\hline Bfd & No & No & No & No \\
\hline$B f i$ & No & No & No & No \\
\hline $\mathrm{Pe}$ & No & No & No & No \\
\hline $\mathrm{Hu}$ & No & No & No & No \\
\hline Uca & No & No & No & No \\
\hline Ucb & No & No & No & No \\
\hline Ucc & No & No & No & No \\
\hline Ucd & No & No & No & Yes $(14>17,18)$ \\
\hline $\mathrm{Sp}$ & No & No & No & No \\
\hline TCT-DP total & No & No & No & Yes $(14>17)$ \\
\hline
\end{tabular}

Completions $(\mathrm{Cm})$. The number of completions for the default elements in the TCT-DP changes significantly across age groups $F(17,4797)=53.98, p<.001, \eta^{2}=.161$. The number of completions grows significantly year by year from the age of four $(M=2.26$; $S D=1.29)$ to the age of nine $(M=4.57 ; S D=.95)$; between the ages of nine and $16(M=4.60 ; S D=1.04)$ the number of completions stabilizes at $17(M=4.30$; $S D=1.36), 18(M=4.41 ; S D=1.25)$ and 19 years of age $(M=4.25 ; S D=1.26)$, 
and then grows again at $20(M=4.92 ; S D=1.14)$ and $21(M=4.94 ; S D=.70)$. Fourteen year old students generate significantly more continuations than students at the ages of $17 t(809)=5.21 ; p<.001, d=.39,18 t(880)=4.03 ; p<.01, d=.29$ and $19 t(373)=3,61$; $p<.05, d=.43$, which indicates the occurrence of a crisis in the development of this ability in early adolescence. However, no crisis in the number of completions at the stage of entry into formal schooling were identified, nor were there any fourth and sixth grade slumps.

New elements ( $\mathrm{Ne})$. The number of new elements appearing in the pictures changes significantly across the age groups $F(17,4797)=9.40, p<.001, \eta^{2}=.032$. The number of new elements rises gradually between the age of four $(M=.82$; $S D=1.44)$ and $15(M=2.22 ; S D=2.20)$ with three statistically non-significant decreases at the ages of seven, 11, and 13. Next, the number of new elements declines at the age of $16(M=1.62 ; S D=1.94)$ and stays at a similar level until the age of $18(M=1.69$; $S D=2.05)$, and then grows significantly at the age of $19(M=2.04 ; S D=2.37)$, and stays at a similar level until the age of $21(M=1.90 ; S D=1.96)$. Despite the downward trend in the number of new elements at the ages of $7,11,13$ as well as 16,17 and 18 no significant crises in the development of this ability were noted.

Connections made with a line $(\mathrm{CI})$. An analysis of variance $F(17,4797)=2.08, p<.01$, $\eta^{2}=.007$ showed, that the number of line connections between each element changes significantly across the age groups. The number of connections increases between the age of four $(M=2.10 ; S D=2.18)$ and six $(M=2.74$; $S D=2.25)$, then falls significantly at the age of seven $(M=2.02 ; S D=2.18)$, rises slightly between seven and 10 years of age $(M=2.44 ; S D=1.95)$ and maintains a similar level across the other age groups, marking statistically non-significant decreases at the ages of 11, 13 and 17. A statistically significant decline in the number of connections made with a line between the ages of six and seven $t(425)=3.62 ; p<.05, d=.35$ may indicate a crisis in the development of this skill at the stage of entry into formal schooling.

Connections that contribute to a theme (Cth). Thematic connections change significantly across the age groups $F(17,4797)=15.02, p<.001, \eta^{2}=.051$. The number of thematic connections gradually rises from age four $(M=1.16 ; S D=1.86)$ to age $14(M=3.90 ; S D=2.50)$ marking three statistically non-significant falls at the ages of 7, 11 and 13. From the age of 14 a notable decrease occurs in the number of thematic connections, which lasts until as late as age $19(M=2.60 ; S D=2.68)$. Later, up to the age of $21(M=4.13 ; S D=2.21)$ a marked rise in the number of thematic connections occurs, which is analogous to that at the age of 14 . Comparisons of thematic connections year by year suggest the presence of a crisis in this ability in early adulthood. 14 year old 
students achieve significantly higher results in the number of thematic connections than 16 year old students: $16(t(568)=4.60, p<.001, d=.39), 17(t(809)=7.01, p<.001$, $d=.52), 18(t(880)=6.98, p<.001, d=.52)$ and $19(t(373)=4.41, p<.001, d=.52)$, and 15 year old students score higher than those at the age of $17(t(691)=4.05, p<.01$, $d=.36)$ and $18(t(762)=3.96, p<.01, d=.35)$.

Boundary breaking that is fragment-dependent (Bfd). The number of instances of using the smaller square outside the frame of the picture varies significantly depending on the age group analyzed $F(17,4797)=3.76, p<.001, \eta^{2}=.013$. The number of instances of making use of this element grows slightly from the age of $4(M=0.25 ; S D=1.18)$ until $19(M=0.91 ; S D=2.14)$ and two statistically non-significant drops at the ages of seven and 11 were noted. Next, there is a significant increase at age $20(M=2.14 ; S D=2.82)$, and at the age of 21 the trend returns to the level before the last peak $(M=1.00$; $S D=2.26$ ). Analyses of the number of instances of small square use from year to year reveals no crises in the development of this ability.

Boundary breaking that is fragment-independent (Bfi). The number of instances of breaking out of the frame changes significantly across the age groups. $F(17,4797)=4.13, p<.001, \eta^{2}=.014$. The number of instances of breaking the boundary declines from the age of four $(M=0.40 ; S D=1.20)$ to the age of six $(M=0.11$; $S D=0.63)$, and then grows gradually until the age of $12(M=0.66$; $S D=1.70)$ with a statistically non-significant fall at age 11. After this period the number of such instances stabilizes and stays at a roughly similar level until the age of $21(M=0.63 ; S D=1.85)$. No crisis in the development of this ability were noted.

Perspective (Pe). The number of instances of applying perspective in the TCT-DP varies significantly across the age groups $F(17,4797)=49.54, p<.001, \eta^{2}=.149$. The number of students making use of perspective grows consecutively from the age of four $(M=0.00 ; S D=0.00)$ until the age of $20(M=1.41$; $S D=1.95)$ with two statistically nonsignificant decreases at the ages of 14 and 16 (see Figure 1). No crises in the development of perspective among the groups analyzed were noted.

Humour and affectivity (Hu). The number of instances of making use of humorous elements in the TCT-DP varies significantly across the age groups $F(17,4797)=18.82$, $p<.001, \eta^{2}=.063$. The number of instances of use of humour grows consistently from the age of four $(M=0.06$; $S D=0.24)$ until the age of $19(M=1.22$; $S D=1.58)$ with a statistically non-significant drop at the age of 11. Analysis of means year by year revealed no crises in the development of humour and affectivity across the age groups. 
Unconventionality - manipulation of the test material (Uca). The number of instances of unusual use of the test sheet did not vary among the age groups $F(17,4797)=1.48$, $p>.05, \eta^{2}=.005$ which signifies a lack of crises in the development of this ability.

Unconventionality - surrealistic or abstract element (Ucb). The number of instances of use of abstract elements to form solutions in the TCT-DP changes significantly across the age groups $F(17,4797)=8.31, p<.001, \eta^{2}=.029$. the number of such solutions increases from age four $(M=0.39 ; S D=1.02)$ do $7(M=0.93 ; S D=1.39)$ and gradually falls off by the age of $15(M=0.29$; $S D=1.82)$ with statistically non-significant growth at the ages of 10,12 and 14. From the age of 15 a clear rise in the number of abstract and surreal elements is observable, and this reaches its peak at $21(M=1.38$; $S D=1.51)$. Despite the clear drop-off in the number of such solutions at age 15, year by year comparison did not reveal any statistically significant differences which might have indicated the occurrence of crises in the development of this ability.

Unconventionality - use of symbols or signs (Ucc). The number of instances of utilizing symbols and signs varies significantly across the age groups $F(17,4797)=7.78$, $p<.001, \eta^{2}=.026$. The number of such solutions grows consistently between the age of $4(M=0.07 ; S D=0.45)$ and $15(M=0.82 ; S D=1.34)$. At age 16 a statistically nonsignificant decrease in the number of such solutions takes place $(M=0.49 ; S D=1.12)$, followed by another rise which lasts until age $20(M=0.86$; $S D=1.37)$. Although there was a marked drop in the number of symbolic solutions between the ages of 15 and 16 , year by year comparison yielded no statistically significant differences which might have been a sign of crises in the development of this ability $(t(450)=2.97, p>.05, d=.24)$.

Unconventionality - unconventional usage of the given fragments (Ucd). The number of non-stereotypical completions of the default elements of the TCT-DP varies significantly across the age groups $F(17,4797)=9.91, p<.001, \eta^{2}=.034$. The number of such completions increased between the ages of four $(M=0.25 ; S D=0.66)$ and $12(M=0.93$; $S D=1.12$ ) with a statistically non-significant fall at the age of 11 . After the age of 12 a gradual decline in such solutions occurred, reaching its lowest level at the age of $17(M=0.47 ; S D=0.90)$ and persisting until the age of $19(M=0.47 ; S D=0.88)$. Later, at the age of $20(M=1.00 ; S D=1.24)$ and $21(M=1.08 ; S D=1.09)$ another rise in the number of non-stereotypical solutions occurred. Year by year comparisons show that students at the age of 14 achieve significantly higher scores on the unconventionality scale than students at the age of $17(t(809)=4.64, p<.001, d=.34)$ and $18(t(880)=3.40$, $p<.001, d=.25)$, which indicates a crisis in the development of unconventionality in early adulthood. 
Speed (Sp). The speed of solving the TCT-DP varies significantly across the age groups $F(17,4797)=14.15, p<.001, \eta^{2}=.048$. The speed increases significantly from the age of four $(M=0.06 ; S D=0.44)$ to the age of $12(M=1.40 ; S D=1.81)$ with a statistically non-significant fall at age 11. After the age of 12 the test-solving speed declines again and reaches its lowest level at the age of $15(M=0.76$; $S D=1.20)$. At the age of $16(M=1.34 ; S D=1.90)$ a statistically significant rise in speed occurs and persists at a similar level until the age of $21(M=1.29 ; S D=1.74)$. No crises in test-solving speed were noted.

Creative abilities - TCT-DP total score. At the final stage of analyses, as follows from the instructions (Urban \&Jellen, 1996), a scores for all of the TCT-DP's criteria was calculated to form a global creative ability score. A one-way analysis of variance showed that the level of creative ability varies among the age groups $F(17,4797)=21.95, p<.001$, $\eta^{2}=.072$. The level of ability increases consistently from the age of $4(M=11.83$; $S D=7.44)$ until the age of $14(M=24.19 ; S D=9.31)$. Three statistically non-significant slumps occur in the level of creative ability at ages seven, 11 and 13. From the age of 14 a minor decrease in creative ability occurs and reaches its lowest level at $17(M=21.61 ; S D=11.09)$. Afterwards, another rise in creative ability occurs, and reaches its highest level at 20 years of age $(M=28.33$; $S D=13.60)$. To summarize, between the ages of 14 and 19 a clear drop in creative ability occurs. Year by year comparisons show that people at the age of 14 have significantly higher levels of creative ability than people at the age of $17(t(809)=3.67, p<.05, d=.27)$, which suggests a crisis in the development of creative ability in the period of early adulthood.

\section{DISCUSSION}

The goal of the study at hand was to analyze trends in the development of creative abilities while paying particular attention to periods of stagnation and potential drop-offs referred to as the entry into formal schooling slump, the 4th grade slump, the 6th grade slump and the adolescent slump. The cross-sectional study conducted involved nearly five thousand persons aged from 4 to 21 at consecutive stages of the Polish education system starting with pre-schoolers, through primary school students, middle-school students, secondary-school students and finally university students.

The research conducted shows changes in levels in 13 out of 14 assessment criteria for the TCT-DP across the analyzed age groups. No change was indicated only in the case of the unconventional manipulation of the test material (Uca). Analyses of developmental trends for each of the test criteria indicated a non-linear process for the development of creativity. These trends are different for each of the criteria of the TCT-DP and 
based on the analyses in figure 1 at least three types may be discerned. In the case of continuations $(\mathrm{Cn})$, completions $(\mathrm{Cm})$, connections that contribute to a theme (Cth), and usage of the given fragments (Ucd) there is a rise in levels from four until approximately nine years of age, followed by a stabilization after the age of 15 , followed by a decrease between the ages of 16 and 18-19, and a rise at the ages of 20 and 21 . Translating the age of the respondents into stages of schooling, it may be concluded that the increase in abilities analyzed begins in kindergarden and continues until the third grade of primary school, then, in grades 4-6 of primary school and in middle school, the investigated abilities maintain more or less the same level, after which, in secondary school, a minor decrease occurs, followed by a rise at university. In the case of new elements $(\mathrm{Ne})$, boundary breaking that is fragment-independent (Bfi) and unconventionality - use of symbols or signs (Ucc) starting at the age of four up until the age of 15, a gradual development takes place, and between the ages of 16 to 18 a decrease occurs, followed by a rise between 19 to 21 . Again, this decline in ability also takes place in secondary school. In the case of perspective $(\mathrm{Pe})$, humor and affectivity $(\mathrm{Hu})$ and boundary breaking that is fragment-dependent $(\mathrm{Bfd})$ one can observe a consistent increase in levels with age.

Analysis of changes in the total score of the TCT-DP at each age strata indicating the level of creative ability also suggests non-linearity in the development of creativity. The level of creative ability grows consecutively from the age of four until 14 . During this period, three minor drop-offs occur at age 7, 11 and 13. After the age of 14 a gradual decline in the level of creative ability occurs, and lasts until age 17 , followed by another rise, which ends at age 20. Analyses of developmental trends suggests that a slowdown in the development of creative ability occurs as early as in middle school, which loses even more momentum in secondary school, indicating an adolescent slump in the development of creativity.

\section{The Slump Caused by Entry Into Formal Schooling}

Among 7-year-olds, that is, students at the beginning of their education in primary school (see Table 3) there was a crisis in just one of the assessment criteria of the TCT-DP connections made with a line $(\mathrm{Cl})$. As for the remaining four scales: new elements $(\mathrm{Ne})$, connections that contribute to a theme (Cth), unconventionality - manipulation of the test material(Uca) and unconventionality - use of symbols or signs (Ucc) we documented only a slight, statistically non-significant decline between the scores of seven and 6-year-olds. The findings may be explained by changes in cognitive development described at the beginning of the paper. What seems to be most significant is the transition from the preoperational stage ranges to the concrete operational stage (Marchand, 2012; Piaget, 1962). 
A strong need for competence among students beginning formal schooling takes the place of creative expression and spontaneity characteristic in early childhood (Erikson, 1968), which may explain the breakdown in scores on the scales of unconventionality manipulation of the test material and unconventionality - use of symbols or signs. Earlier, i.e. at the end of kindergarten education (6-year-olds) a minor decline in TCT-DP scores occurred in the criteria of boundary breaking that is fragment-independent and speed. The criterion concerns relaxing one's approach towards the strict requirement of sticking to the confines of the sheet or the figure's boundaries. As Urban suggests (1991) the requirement of sticking to the frame and not going beyond the set boundaries is introduced at the beginning of school in the process of learning to write and colour figures, which may explain the lower scores among 6-year-olds. The decline in scores among 7-yearolds may stem from the influence of school (kindergarten vs. school), which corresponds with TCT-DP results obtained by Urban (1991) among 6-year-old German 1st grade students at primary school. Similar changes, declines in divergent performances after school enrollment at approximately age 7 - the transition from the 1 st to the 2 nd school year were noted in samples from both Luxembourg and German (Krampen, 2012). The results are a powerful empirical confirmation of the hypothesis of Torrance (1963).

\section{The 4th Grade Slump}

We noted no clear decline in creative abilities upon transition between lower grades (1st to 3rd) to higher (4th to 6th) of primary school. This means that the so-called "fourth grade slump" (see table 3) suggested by Torrance (1968) was not confirmed. These results are consistent with those obtained with the same tool in a German sample (Jaarsveld et al., 2012) and a Polish sample (Jastrzębska \& Limont, 2015). The Polish authors also noted that the specific plateau phase began at age 10 and lasted until age 13, whereas it occurred only after the age of 12 in Urban's (2005) research. In our research, we observed a minor downward trend among 10-year-olds only in the case of completions $(\mathrm{Cm})$. In the vast majority of the TCT-DP criteria 10-year-olds achieved even slightly higher scores than 9-year-olds. Characteristically, a slight decline in creative ability was noted among 11-year-olds. The slumps include criteria such as: total TCT-DP score, new elements $(\mathrm{Ne})$, connections made with a line $(\mathrm{Cl})$, connections that contribute to a theme (Cth), boundary breaking that is fragment-dependent (Bfd), boundary breaking that is fragment-independent (Bfi), humor and affectivity $(\mathrm{Hu})$, unconventionality - manipulation of the test material (Uca), unconventionality - surrealistic or abstract element (Ucb), unconventionality - use of symbols or signs (Ucc) and speed (Sp). 


\section{The 6th Grade Slump}

We noted no significant decline in creative ability indicative of the 6th grade slump. We did however unveil a number of statistically non-significant drops in the levels of creative ability among 13-year-olds in the total TCT-DP score, continuations (Cn), new elements $(\mathrm{Ne})$, connections made with a line $(\mathrm{Cl})$, connections that contribute to a theme (Cth), boundary breaking that is fragment-independent (Bfi), unconventionality - surrealistic or abstract element (Ucb), unconventionality - use of symbols or signs (Ucc), usage of the given fragments (Ucd) and speed (Sp). One may suppose that along with transitioning to consecutive stages of education, especially at the stage of transitioning from primary to middle school, features attributed to creative ability such as unconventionality, boundary breaking or applying one's own graphic structure and theme to the piece may be only slightly impeded by school discipline and the need to adapt to rules, norms or the demands of adults. This is integrated with cognitive and psychosocial development, as it is linked to a shift in perspective from the egocentric to the sociocentric (Runco \& Charles, 1997), transitioning from the preoperational stage ranges to the concrete operational stage (e.g. Marchand, 2012; Piaget, 1962), and the child's transition from the preconventional to conventional stages of moral development (Kohlberg, 1981). It seems that at this point, the development of creative abilities is not critical and is merely a certain type of prelude to deeper change about to occur in adolescence.

\section{The Adolescent Slump}

The findings of our study confirm the occurrence of the adolescent slump in the case of completions $(\mathrm{Cm})$, connections that contribute to a theme (Cth), usage of the given fragments (Ucd) and total TCT-DP score. Based on the analyses of changes occurring at the time of maturation, one can note a clear and statistically significant drop in creative ability which begins at about age 15, reaching critical levels at the age of 17 . Furthermore, we noted a statistically non-significant trend towards a decline in the levels of creative ability in the case of continuations $(\mathrm{Cn})$, new elements $(\mathrm{Ne})$, connections made with a line $(\mathrm{Cl})$, connections that contribute to a theme (Cth), boundary breaking that is fragment-independent (Bfi), unconventionality - surrealistic or abstract element (Ucb), unconventionality - use of symbols or signs (Ucc) and usage of the given fragments (Ucd). These drops may at least be partially explained by the developmental crisis noted at this age (i.e. Erikson, 1959). The formation of identity entails the need to adjust to social norms and rules set out by peers. Such attempts to disambiguate and identify with a certain group undertaken by the adolescent may have negative impact on the originality of their thinking (Barbot \& Heuser,' in press; Dollinger, et al., 2005). These changes may 
also be related to the crisis in self-concepts especially in creative self-efficacy and creative personal identity. It was noted that following the rise of scores in self-beliefs at ages 13-15, a noticeable decline occurs among 16- to 18-year-olds, followed by another rise in early adulthood (18-24 years) reaching a level which persisted until late adulthood (Karwowski, 2015).

Another reason behind the crisis in creative abilities may be the previously mentioned rapid developmental changes in the brain which occur throughout maturation (Blakemore \& Choudhury, 2006), especially the decrease of grey matter (Raznahan et al., 2010). The crisis concerning unconventionality - surrealistic or abstract elements (Ucb), previously confirmed by Rudowicz (2004) may be related to the stage of conventional drawing, typical for teenagers, when they focus more on the representational accuracy of their art than its novelty or aesthetic value (Rosenblatt \& Winner, 1988; Popek, 2010). The fact that the TCT-DP is a graphic test which refers to the figural domain is also not without significance. At this stage of life the creative dimension of imagination changes its nature from the visual to the conceptual (Vygotsky, 1930/2004) and interest in unconstrained expression through drawing decreases.

The confirmed adolescent slump in creative ability between the ages of 15 and 17-18 spans the period ending middle school and the entire duration of secondary school. Since there is a visible decline in creative ability at this time, it may be stipulated that creative activity is not a key value for youth. Nevertheless, this is when teenagers make decisions concerning their further education and, as a result, the choice of their profession. Such a situation may lead to missing out on opportunities to make use of young people's creative potential in their adult professional activities.

The discerned decline in creative ability over this period casts a shadow on the means of education at this stage of schooling. Perhaps teachers focus too much on the students' intellectual potential and their educational achievements rather than on developing their creativity (Gralewski \& Karwowski, 2012, 2013). The relationships between levels of creative ability and school performance (GPA) in Polish schools may lie between $r=-.64$ and $r=.76$; in schools where creative abilities are most strongly linked to educational outcomes, the role of intelligence is relatively small, and in schools where intelligence is the key factor, the relationship between creative abilities and the students' scores are the weakest (Gralewski \& Karwowski, 2012). Unfortunately the latter model, in which intelligence not creativity is the key characteristic of a student's performance, is most common (Gralewski \& Karwowski, 2012). This may suggest that in Polish high schools developing students' creativity is an exception to the rule, which may in turn re- 
sult in impeding the development of these kinds of abilities at this stage of education. This conclusion is to some extent, supported by the results of other studies (Gralewski \& Karwowski, 2013, 2016) in which teachers in Polish high schools do not fare well in recognizing students' creativity. One in three teachers in Polish high schools have misconceptions about the traits characterizing creative students and, as a result, the teacher's grading does not correlate with the levels of creative potential of the student as measured by standardized activity questionnaires (Gralewski \& Karwowski, 2016). The conclusions outlined above regarding the underestimation of students' creativity, erroneous preconceptions regarding the characteristics of creative students, and the lack of ability to recognize creativity by high school teachers in Poland may contribute to the crisis of development of creativity in early adulthood observed in our study.

\section{Limitations}

While analyzing the results of our research one must take into consideration their crosssectional nature. In attempting to include people from early childhood to early adulthood in our study we were forced to conduct a cross-sectional study. As a result, one of the greatest strengths of our study becomes one of its greatest weaknesses. In practice the differences in creative ability between each age group may stem from reasons other than just developmental changes, which could only be ruled out in long-term longitudinal studies.

\section{General Discussion}

The results presented provide arguments in favour of the claim concerning the non-linear nature of the development of creative ability from early childhood to early adulthood (Barbot, Lubart, \& Besançon, 2016). The findings obtained correspond with results from previous research (Besançon \& Lubart, 2008; Kleibeuker et al., 2013).

While analyzing the average levels of each of the TCT-DP test criteria we indicated at least three different trajectories for their development. The first suggests a rise in creative ability between the age of nine, followed by a stagnation beginning at about 15 years of age, with a minor decline between ages 16 and 18-19, superseded by another rise. The second of the trends suggests a successive rise in creative ability from the age of 15, after which a decline occurs between the ages of 16 and 18-19, followed by a rise. Finally, the third trajectory suggests consistent growth in the levels of creative ability with age, which persist until early adulthood. Comparisons of average levels of creative abilities year by year as measured with the TCT-DP unambiguously confirm the occurrence of the adolescent slump in the development of creativity. The adolescent slump was confirmed for 3 of the 14 criteria and the total TCT-DP score. It spans the entire duration of secondary school and may be of significance for decisions concerning professional development 
and further schooling at the level of higher education. Thus the creative crisis in this period may be of significance for decisions concerning future professional activities. The analyses did not confirm the existence of the fourth and sixth grade slumps. Only in the case of one criterion was there a slump confirmed as being caused by entry into formal schooling.

\section{REFERENCES}

Alfonso-Benlliure, V., \& Santos, M. R. (2016). Creativity development trajectories in Elementary Education: Differences in divergent and evaluative skills. Thinking Skills and Creativity, 19, 160-174. http://dx.doi.org/10.1016/j.tsc.2015.11.003

Alpaugh, P. K., Parham, I. A., Cole, K. D., \& Birren, J. E. (1982). Creativity in adulthood and old age: An exploratory study. Educational Gerontology, 8, 101-116.

Ayman-Nolley, S. (1992). Vygotsky's perspective on the development of imagination and creativity, Creativity Research Journal, 5(11), 77-85.

Barbot, B., \& Heuser, B. (in press). Creativity and the Identity Formation in Adolescence: a Developmental Perspective. In. Karwowski, M. \& Kaufman, J. C. (Eds.), Creativity and the Self. Academic Press

Barbot, B., \& Tinio, P. P. L. (2015). Where is the " $g$ " in creativity? A specialization differentiation hypothesis. Frontiers of Human Neuroscience, 8, 1041. doi: 10.3389/ fnhum.2014.01041.

Barbot, B., Lubart, T. I. \& Besançon, M. (2016). "Peaks, slumps, and bumps": Individual differences in the development of creativity in children and adolescents. In B. Barbot (Ed.), Perspectives on creativity development. New Directions for Child and Adolescent Development, 151, 27-39.

Benedek, M., Jauk, E., Fink, A., Koschutnig, K., Reishofer, G., Ebner, F., \& Neubauer, A. C. (2013). To create or to recall? Neural mechanisms underlying the generation of creative new ideas. Neurolmage, 88, 125-133.

Besançon, M., \& Lubart, T. I. (2008). Differences in the development of creative competencies in children schooled in diverse learning environments. Learning and Individual Difference, 18, 381-389.

Blakemore, S. J., Choudhury, S. (2006). Development of the adolescent brain: implications for executive function and social cognition. Journal of Child Psychology and Psychiatry 47(3/4), 296-312

Camp, G. C. (1994). A longitudinal study of correlates of creativity. Creativity Research Journal, 7, 125-144. 
Chae, S. (2003). Adaptation of a picture-type creativity test for pre-school children. Language Testing, 2, 178-188.

Charles, R. E. \& Runco, M. A. (2000-2001). Developmental trends in the evaluative and divergent thinking of children. Creativity Research Journal, 13(3\&4), 417-437.

Cheung, P. C., Lau, S., Chan, D. W., \& Wu, W. Y. H. (2004). Creative potential of school children in Hong Kong: Norms of the Wallach-Kogan Creativity Tests and their implications. Creativity Research Journal, 16(1), 69-78.

Claxton, A. F., Pannells, T. C., \& Rhoads, P. A. (2005). Developmental trends in the creativity of school-age children. Creativity Research Journal, 17(4), 327-335.

Fearon, D. D., Copeland, D. \& Saxon, T. F. (2013). The Relationship Between Parenting Styles and Creativity in a Sample of Jamaican Children. Creativity Research Journal, 25, 1, 119-128, DOI:10.1080/10400419.2013.752287.

Cropley, A. J. (2001). Creativity in education and learning. a guide for teachers and educators. London: Kogan Page.

Dahlman, S., Bäckström, P., Bohlin, G., Frans, Ö. (2013). Cognitive abilities of street children: low-SES Bolivian boys with and without experience of living in the street. Child Neuropsychology, 19, 5, 540-556, http://dx.doi.org/10.1080/09297049.2012.731499.

Daugherty, M. (1993). Creativity and private speech: Developmental trends. Creativity Research Journal, 6, 287-296. Diamond, A. (2002). Normal development of prefrontal cortex from birth to young adulthood: Cognitive functions. anatomy. and biochemistry. In D.T. Stuss \& R.T. Knight (Eds.), Principles of frontal lobe function (pp. 466-503). London. UK: Oxford University Press.

Diamond, A. (2002). Normal development of prefrontal cortex from birth to young adulthood: Cognitive functions. anatomy. and biochemistry. In D.T. Stuss \& R.T. Knight (Eds.), Principles of frontal lobe function (pp. 466-503). London. UK: Oxford University Press.

Dietrich, A. (2004). The cognitive neuroscience of creativity. Psychonomic Bulletin \& Review 11, 1011-1026.

Dollinger, S. J., Dollinger, S. M. C., \& Centeno, L. (2005). Identity and creativity. Identity: An International Journal of Theory and Research, 5 (4), 315-339.

Erikson, E. H. (1959). Identity and the Life Cycle. New York: International Universities Press.

Erikson, E. H. (1968). Identity - youth and crisis. New York: Norton

Gardner, H. (1982). Art. mind. and brain: A cognitive approach to creativity. New York: Basic Books

Gralewski, J., \& Karwowski, M. (2012). Creativity and school grades: A case from Poland. Thinking Skills and Creativity, 7, 198-208. 
Gralewski, J., \& Karwowski, M. (2013). Polite girls and creative boys? Students' gender moderates accuracy of teachers' ratings of creativity. Journal of Creative Behavior, 47(4), 290-304.

Gralewski, J., \& Karwowski, M. (2016 in press). Are teachers' implicit theories of creativity related to the recognition of their students' creativity? The Journal of Creative Behavior, Vol. 0, Iss. 0, pp. 1-17, DOI: 10.1002/jocb.140

Guilford, J. P. (1967). The nature of human intelligence. New York: McGraw-Hill.

Hassler, M., \& Nieschlag, E. (1989). Masculinity, femininity, and musical composition psychological and psychoendocrinological aspects of musical and spatial faculties. Archives of Psychology, 141(1), 71-84.

He, W., \& Wong, W. (2015, in press) Creativity slump and school transition stress: A sequential study from the perspective of the cognitive-relational theory of stress. Learning and Individual Differences. http://dx.doi.org/10.1016/j.lindif.2015.08.034

Jaarsveld, S., Lachmann, T., \& van Leeuwen, C. (2012). Creative reasoning across developmental levels: Convergence and divergence in problem creation. Intelligence, 40, $172-188$.

Jastrzębska, D., Limont, W. (2015, July). Cross-sectional of Creative Abilities of Polish students from 7 to 18. Poster session presented at the Excellence and Innovation in Education: The Creativity - Innovation Challenge, ICIE Jagiellonian University Conference, Kraków, Poland.

Karwowski, M. (2015). Development of the Creative Self-Concept. Creativity. Theories Research, 2, 2, 165-179.

Karwowski, M., \& Lebuda, I. (in press). Written on the Writer's Face: Facial Width-toHeight Ratio among Nominees and Laureates of the Nobel Prize in Literature. Creativity Research Journal.

Karwowski, M., \& Lebuda, I. (2014). Digit ratio predicts eminence of Polish actors. Personality and Individual Differences, 64, 30-34.

Kim, K. H. (2011). The creativity crisis: The decrease in creative thinking scores on the Torrance Tests of Creative Thinking. Creativity Research Journal, 23(4), 285-295.

Kleibeuker, S. W,. de Dreu, C. K. W, . \& Crone, E. A. (2013). The development of creative cognition across adolescence: Distinct trajectories for insight and divergent thinking. Developmental Science, 16, 2-12.

Kohlberg, L. (1981). The Philosophy of Moral Development: Moral Stages and the Idea of Justice. San Francisco: Harper \& Row. 
Krampen, G. (2012). Cross-sequential results on creativity development in childhood within two different school systems: Divergent performances in Luxemburg versus German kindergarten and elementary school students. Europe's Journal of Psycholo$g y, 8(3), 423-448$.

Lau, S., \& Cheung, P. C. (2010). Developmental trends of creativity: What twists of turn do boys and girls take at different grades? Creativity Research Journal, 22(3), 329-336.

Levy, B., \& Langer, E. (1999). Aging. In M. A. Runco \& S. R. Pritzker (Eds.), Encyclopedia of Creativity (Vol. 1, pp. 45-52). New York: Academic Press.

Lopez, E. C., Esquivel, G. B., \&Houtz, J. C. (1993). The creative skills of culturally and linguistically gifted and diverse students. Creativity Research Journal, 6, 401-412.

Lubart, T. I., \&Lautrey, J. (1995). Relationships between creative development and cognitive development. In Paper presented at the 7th European Conference on Developmental Psychology Krakow, Poland. Maker, C. J., Jo, S., \& Muammar, O. M. (2008). Development of creativity: The influence of varying levels of implementation of the DISCOVER curriculum model. a non-traditional pedagogical approach. Learning and Individual Differences, 18, 402-417.

Maker, C. J., Jo, S., Muammarb, O. M. (2008). Development of creativity: The influence of varying levels of implementation of the DISCOVER curriculum model, a nontraditional pedagogical approach. Learning and Individual Differences, 18, 402-417

Marchand, H. (2012). Contributions of Piagetian and post-Piagetian theories to education, Educational Research Review, 7, 165-176

Marcia, J. E. (1994). The empirical study of ego identity. In H. A. Bosma \& L. G. Tobi (Eds.), Identity and development: An interdisciplinary approach (pp. 67-80). Thousand Oaks. CA: Sage.

Marcon, R. A. (1995). Fourth-grade slump: The cause and cure. Principal, 74(5), 16-17.

McCrae, R. R., Arenberg, D., \& Costa, P. T. (1987). Declines in divergent thinking with age: Cross-sectional. longitudinal. and cross-sequential analyses. Psychology and Aging, 2, 130- 137.

Nelson, E. E., Guyer, A. E. (2011). The development of the ventral prefrontal cortex and social flexibility. Developmental Cognitive Neuroscience 1, 233-245

Piaget, J. (1950). The psychology of intelligence. New York: Harcourt Brace.

Piaget, J. (1962). Play, dreams and imitation in childhood. New York: Norton.

Popek, S. (2010). Psychologia twórczości plastycznej. Kraków: Wydawnictwo Impuls.

Raznahan, A., Lee, Y., Stidd, R., Long, R., Greenstein, D., Clasen, L., Addington, A., Gogtay, N., Rapoport, J. L., \& Giedd, J. N. (2010). Longitudinally mapping the influence of sex and androgen signaling on the dynamics of human cortical maturation in adolescence. Proceedings of the National Academy of Sciences, 107 (39), 16988-16993 
Romo, M., Alfonso-Benlliure \& Sánchez-Ruíz, M. J. (2008). T.C.I. Test de Creatividadlnfantil. Madrid: TEA Ediciones.

Rosenblatt, E., \& Winner, E. (1988). The art of children's drawings. Journal of Aesthetic Education, 22, 3-15.

Rothenberg, A. (1990). Creativity in adolescence. Psychiatric Clinics of North America, 13, 415-434.

Rudowicz, E. (2004). Applicability of the Test of Creative Thinking-Drawing Production for Assessing Creative Potential of Hong Kong Adolescents, Gifted Child Quarterly, 48, 3, 202-218.

Runco, M. A. (1991). The evaluative, valuative, and divergent thinking in children. Journal of Creative Behavior, 25, 311-319.

Runco, M. A. (1999). A longitudinal study of exceptional giftedness and creativity. Creativity Research Journal, 12, 161-164.

Runco, A. M., \& Charles, R. E. (1997). Creative potential and performance. In M. A. Runco (Eds.), Creativity Research Handbook (pp. 113-152). Cresskill, NJ: Hampton.

Sak, U., \& Maker, C. J. (2006). Developmental variation in children's creative mathematical thinking as a function of schooling, age, and knowledge. Creativity Research Journal, 18(3),279-291.

Smith, G. J. W., \& Carlsson, I. (1983). Creativity in early and middle school years. International Journal of Behavioral Development, 6, 167-195.

Smith, G. J. W., \& Carlsson, I. M. (1985).Creativity in middle and late school years. International Journal of Behavioral Development, 8, 329-343.

Smith, G. J., \& Carlsson, I. M. (1990). The creative process: A functional model based on empirical studies from early childhood to middle age. Madison. CT: International Universities Press.

Smolucha, L., \&Smolucha, F. (1985). A fifth Piagetian stage: The collaboration between analogical and logical thinking in artistic creativity. Visual Arts Research, X, 90-99.

Spear, L. P. (2013). Adolescent neurodevelopment. Journal of Adolescent Health, 52, S7S13. doi: 10.1016/j.jadohealth.2012.05.006.

Torrance, E. P. (1963). Education and the creative potential. Minneapolis, MI: University of Minnesota Press.

Torrance, E. P. (1968). A longitudinal examination of the fourth grade slump in creativity. Gifted Child Quarterly, 12, 195-199.

Torrance, E. P. (1977). Creativity in the classroom. Washington, DC: National Education Association. 
Urban, K. K. (1990). Recent trends in creativity research and theory in Western Europe. European Journal for High Ability, 1, 99-113.

Urban, K. K. (1991). On the development of creativity in children. Creativity Research Journal, 4 (2), 177-191. DOI: 10.1080/10400419109534384.

Urban, K. K. (2005). Assessing creativity: The Test for Creative Thinking-Drawing Production (TCT-DP). International Education Journal, 6, 272-280.

Urban, K. K., \& Jellen, H. G. (1996). Test for Creative Thinking-Drawing Production (TCT$D P)$. Lisse, Netherland: Swets and Zeitlinger.

Vygotsky, L. S. (1930/2004). Imagination and creativity in childhood. Journal of Russian and East European Psychology, 42, 7-97.

Vygotsky, L. S. (1931/1991). Imagination and creativity in the adolescent. Soviet Psychology, 29, 73-88.

Vygotsky, L. S. (1934/1986). Thought and language. Cambridge, MA: MIT Press, 1986.

Zabelina, D. L., O'Leary, D., Pornpattananangkul, N., Nusslock, R., \& Beeman, M. (2015). Creativity and sensory gating indexed by the P50: Selective versus leaky sensory gating in divergent thinkers and creative achievers. Neuropsychologia, 69, 77-84.

Zedelius, C. M., \& Schooler, J. W. (2015). Mind wandering "Ahas" versus mindful reasoning: alternative routes to creative solutions. Frontiers in Psychology, 6, 834. doi: 10.3389/fpsyg.2015.00834.

Corresponding author at: Ewa Wiśniewska, Creative Education Lab, The Maria Grzegorzewska University, 40 Szczesliwicka St., 02-353 Warsaw, Poland

E-mail: ewawisniewska@aps.edu.pl 